\title{
Cost-effectiveness and resource use of implementing MRl-guided NACT in ER-positive/HER2-negative breast cancers in The Netherlands
}

\author{
Anna Miquel-Cases ${ }^{1}$, Lotte M. G. Steuten ${ }^{2}$, Lisanne S. Rigter ${ }^{3}$ and Wim H. van Harten ${ }^{1,4^{*}}$
}

\begin{abstract}
Background: Response-guided neoadjuvant chemotherapy (RG-NACT) with magnetic resonance imaging (MRI) is effective in treating oestrogen receptor positive/human epidermal growth factor receptor-2 negative (ER-positive/HER2-negative) breast cancer. We estimated the expected cost-effectiveness and resources required for its implementation compared to conventional-NACT.

Methods: A Markov model compared costs, quality-adjusted-life-years (QALYs) and costs/QALY of RG-NACT vs. conventional-NACT, from a hospital perspective over a 5 -year time horizon. Health services required for and health outcomes of implementation were estimated via resource modelling analysis, considering a current (4\%) and a full (100 \%) implementation scenario.

Results: RG-NACT was expected to be more effective and less costly than conventional NACT in both implementation scenarios, with $94 \%$ (current) and $95 \%$ (full) certainty, at a willingness to pay threshold of $€ 20.000 /$ QALY. Fully implementing RG-NACT in the Dutch target population of 6306 patients requires additional $5335 \mathrm{MRI}$ examinations and an (absolute) increase in the number of MRI technologists, by $3.6 \mathrm{fte}$ (full-time equivalent), and of breast radiologists, by $0.4 \mathrm{fte}$. On the other hand, it prevents 9 additional relapses, 143 cancer deaths, 23 congestive heart failure events and 2 myelodysplastic syndrome/acute myeloid leukaemia events.
\end{abstract}

Conclusion: Considering cost-effectiveness, RG-NACT is expected to dominate conventional-NACT. While personnel capacity is likely to be sufficient for a full implementation scenario, MRI utilization needs to be intensified.

Keywords: Cost-effectiveness, Resource utilization, Breast cancer, Neoadjuvant chemotherapy, Response monitoring, MRI

\section{Background}

Neoadjuvant (preoperative) chemotherapy (NACT) is equally effective as adjuvant chemotherapy in breast cancer [1], while offering the possibility of tailoring therapy based on tumour response at monitoring [2]. Among non-invasive imaging modalities for response monitoring, contrast-enhanced magnetic resonance imaging (MRI) is generally regarded as the most accurate for invasive breast

\footnotetext{
* Correspondence: w.v.harten@nki.nl

'Department of Psychosocial Research and Epidemiology, Netherlands Cancer Institute, Plesmanlaan 121, Amsterdam 1066 CX, The Netherlands ${ }^{4}$ Department of Healthcare Technology and Services Research, University of Twente, Drienerlolaan 5, 7522 NB Enschede, The Netherlands

Full list of author information is available at the end of the article
}

cancer. It has good correlation with pathologic complete response (pCR), the most reliable surrogate endpoint of survival [3-5].

Researchers in the Netherlands Cancer Institute (NKI) have previously published criteria for monitoring NACT response with MRI [6]. The research confirmed its prediction for $\mathrm{pCR}$ in the triple negative breast cancer subtype [7], but not in oestrogen receptor-positive $(\mathrm{ER}+)$ and epidermal growth factor receptor 2- negative (HER2-) tumours. This was not an unexpected finding, given the known low rates of $\mathrm{pCR}$ in ER-positive/HER2-negative tumors $[8,9]$ make it an unsuitable measure of tumour response in these tumours. Hence, to investigate their 
benefit from response-guided NACT (RG-NACT), a subsequent study from this group used serial MRI response monitoring as a readout of response [10]. In this study, unresponsive tumours to the first chemotherapy regimen were switched to a second, presumably, 'non-cross-resistant' regimen. Upon study completion, the tumour size reduction caused by the non-cross-resistant regimen was similar to that in initially responding tumours after the first regimen. Furthermore, relapse frequency in both groups was similar. These observations suggested that ER-positive/HER2-negative tumours do benefit from RG-NACT with MRI, despite not reaching $\mathrm{pCR}$. These results are in line with those from the German Breast Group [11], which also showed survival advantage from RG-NACT in ER+ patients.

Compared to traditional NACT, RG-NACT has thus shown to positively influence ER-positive/HER2-negative patients' survival, yet comes at additional monitoring costs. Its onset costs may however be offset by a reduction in the subsequent medical costs. This can be explored via probabilistic cost-effectiveness analysis (CEA), which quantifies the probability and extent to which RGNACT is expected to be cost-effective compared to conventional NACT as based on current evidence. Such information is of interest for health-care regulators who, under the pressure of limited resources, are increasingly using cost-effectiveness as a criterion in decision-making [12].

An important goal for decision-makers is the implementation of cost-effective health-care interventions into routine clinical practice. Yet this can often be jeopardized by the lack of attention given to resource demands [13]. Implementation as described in a CEA may not always be feasible, as this assumes that all physical resources (i.e., doctors, scanners, drugs) required by the new strategy are immediately available, regardless of actual supply constraints (or likely demand). Ignoring these constraints may result in negative consequences, from low levels of implementation through to the technology not being implemented at all [13]. Resource modelling is a method that quantitatively captures the resource implications of implementing a new technology. While this approach has scarcely been used in health-care decision-making, it can be of great help to health services planners who are challenged by implementation issues normally not addressed in CEAs.

Our aim is thus to estimate the expected costeffectiveness and resource requirements of implementing RG-NACT with MRI for the treatment of ER-positive/HER2-negative breast cancers using The Netherlands as a case study population.

\section{Methods}

This study followed the Consolidated Health Economic Evaluation Reporting Standards (CHEERS) checklist and did not require ethical approval [14].

\section{Treatment strategies}

Two strategies were considered for the treatment of ERpositive/HER2-negative breast cancer women; RG-NACT and conventional-NACT (Fig. 1). RG-NACT followed our single-institution neoadjuvant chemotherapy program [10]: treatment with NACT 1 (AC, doxorubicin $60 \mathrm{mg} \mathrm{m-2}$ and cyclophosphamide $600 \mathrm{mg} \mathrm{m}-2$ on day 1 , every 14 days, with PEG-filgrastim on day 2) for three courses (3x) followed by MRI scanning and subsequent classification into 'favourable' or 'unfavourable' responders to NACT defined by previously published criteria [6]. In short, reduction of more than $25 \%$ in the largest diameter of the tumour at late enhancement on the interim MRI relative to the baseline MRI was regarded as a 'favourable' response. All other responses were classified as 'unfavourable'. Favourable patients continue with additional $3 \times$ NACT 1 , and unfavourable patients switch to $3 \times$ NACT 2 (DC, docetaxel $75 \mathrm{mg} \mathrm{m}-2$ on day 1 , every 21 days and capecitabine $2 \times 1000 \mathrm{mg} \mathrm{m}-2$ on days 1-14). Conventional-NACT represented current practice: treatment with $6 \times \mathrm{AC}$. Following NACT, all patients underwent surgery, radiation therapy when indicated and at least 5-years of endocrine treatment according to protocol.

\section{Implementation scenarios}

We performed the cost-effectiveness and resource modelling analysis for two implementation scenarios in the Netherlands, i.e. current implementation and full implementation. These scenarios were adopted in a hypothetical cohort of 6306 patients, reflecting the Dutch target population of stage II/III ER-positive/HER2-negative breast cancers. These are patients with the same baseline characteristics as those of our neoadjuvant chemotherapy program, and thus, where RG-NACT seems beneficial [10]. The current implementation scenario is defined as the number of stage II/III ERpositive/HER2-negative breast cancer patients currently treated with RG-NACT divided by all stage II/III ERpositive/HER2-negative breast cancer patients. The full implementation scenario considers the use of RG-NACT in the entire stage II/III ER-positive/HER2-negative breast cancer population. Although this is not entirely likely, there is always a percentage of non-compliant providers, we decided to present the maximum possible resource use of RG-NACT. The number of patients currently treated with RG-NACT was calculated as the number of scans performed in the Netherlands (assuming $1 \mathrm{scan} /$ patient) [15] minus the number of scans performed for other disease areas than oncology [16], other cancers than breast [17], other applications than guiding response to therapy [18], other stages than II/III [19], and other receptor expressions than ER-positive/ HER2-negative [20]. The entire stage II/III ER-positive/ HER2-negative breast cancer population was estimated 


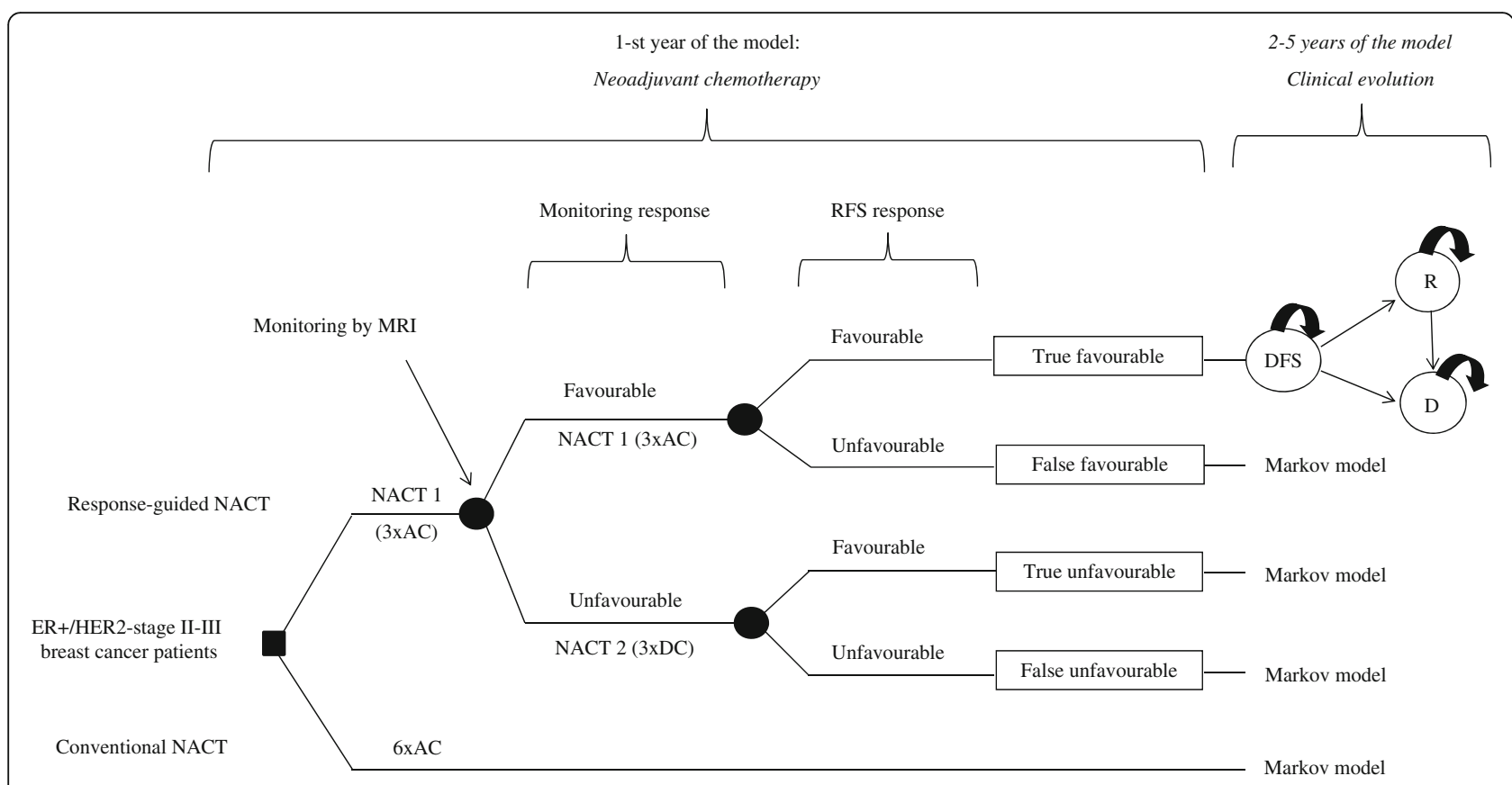

Fig. 1 Decision analytic model to compare the health-economic outcomes of treating ER-positive/HER2-negative stage II-III breast cancer patients with response-guided NACT vs. conventional-NACT. Decision nodes ( $\mathbf{\square})$; patient or health provider makes a choice. Chance nodes $(\bullet)$; more than one event is possible but is not decided by neither the patient or health provider. Abbreviations: NACT= neoadjuvant chemotherapy; RFS = relapse free survival; DFS = disease free survival; $R=$ relapse; $D=$ death; $A C=$ cyclophosphamide, doxorubicine; $D C=$ docetaxel, capecitabine

by multiplying the 2013 breast cancer incidence in the Netherlands (The Netherlands Cancer Registry) by the proportion of patients with stage II/III ER-positive/HER2negative breast cancer (calculations presented in Table 1).

\section{Model overview}

We developed a Markov model to estimate mean differences in clinical effects and costs of treatment with RG-NACT vs. conventional-NACT from a Dutch hospital perspective. For each treatment strategy, the model simulated the transitions of a hypothetical cohort of stage II/III ER-positive/HER2-negative breast cancer patients of 50 years old over three healthstates: disease free (DFS), relapse ( $R$, including local, regional and distant) and death ( $\mathrm{D}$, including breast cancer and non-breast cancer), during a 5-year time horizon (Fig. 1). The model was programmed in Microsoft Excel (Redmond, Washington: Microsoft, 2007. Computer Software).

Upon completion of the NACT intervention, patients in each cohort entered the model in the DFS state (Fig. 1). Patients treated under the RG-NACT strategy entered the DFS model state classified as true-favourable, trueunfavourable, false-favourable and false-unfavourable respondents of NACT at monitoring by using the 5 -year RFS (relapse free survival) as the "gold standard" for NACT response. This was considered a sensible assumption to capture all relapses related to NACT response [21]. Definitions for true-favourable, trueunfavourable, false-favourable and false-unfavourable respondents are presented in Table 2.

In year 1 of the DFS health-state, patients were attributed the costs and health related quality-of-life (HRQoL) of the NACT intervention, except when there was an incidental MRI finding or when they suffered from chemotherapy-related toxicities (Terminology for Adverse Events grades 3 and 4 [22]); vomiting, neutropenia, handfoot-syndrome (HFS), desquamation and congestive heart failure (CHF) [23, 24]). In these situations, there was NACT interruption and temporary changes in costs and HRQoL, except for HFS and desquamation. For these toxicities there is no other curative treatment than time, thereby, they were exempt of costs. From the DFS health-state, patients could either move to the $R$ health-state, i.e., 'relapse event'; move to the $\mathrm{D}$ healthstate, i.e., 'non-breast cancer death event'; or stay in the DFS health-state, i.e., 'no event'. From the R health-state, patients could either move to the $\mathrm{D}$ health-state, i.e., 'breast cancer or non-breast cancer related death event'; or stay in the $\mathrm{R}$ health-state, i.e., 'cured relapse'. We assumed that patients could only develop one relapse. In the 5th-year of the model, patients could incur long-term NACT-related toxicities, including myelodysplastic syndrome (MDS) and acute myeloid leukaemia (AML) [25]. 
Table 1 Current implementation scenario calculation [15-20, 54]

Formula to derive current implementation of response-guided NACT in the Netherlands:

Number of stage II-III, ER+/HER2-breast cancer currently treated with response-guided NACT

Number of eligible stage II-III, ER+/HER2-breast cancer

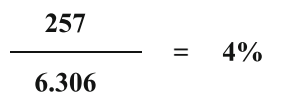

\# Source

Calculations of the number of stage II-III, ER+/HER2-breast cancer currently treated with response-guided NACT

\begin{tabular}{lll}
\hline MRI scans performed in the Netherlands & 843.765 & {$[15]$} \\
in oncology & 202.503 & {$[16]$} \\
$\quad$ for response-guided NACT & 2.430 & {$[18]$} \\
$\quad$ in stage II-III, ER+/HER2- breast cancer & $\mathbf{2 5 7}$ & {$[17,19,20]$}
\end{tabular}

Calculations of number of eligible stage II-III, ER+/HER2-breast cancer

\begin{tabular}{ccc}
\hline Incidence of breast cancer patients in the Netherlands & 14.326 & {$[54]$} \\
With stage II-III, ER+/HER2-breast cancer & $\mathbf{6 . 3 0 6}$ & {$[17,20]$}
\end{tabular}

\section{Model input parameters}

Input model parameters are presented in Table 3.

\section{Clinical}

The proportions of favourable and unfavourable patients at monitoring and after 5-years of NACT were retrieved from an updated version of the individual patient data from Rigter et al. [10]. The transition probabilities (tp) simulating a relapse and a breast cancer death event were derived from Kaplan-Meyer (KM) curves. The first from a KM of RFS (interval from finishing the NACT intervention to occurrence of first relapse) and the second, from a KM of breast cancer specific survival (BCSS; interval from relapse to occurrence of breast cancer death). The KMs were either constructed uniquely with raw data of Rigter et al. [10], or by using additional assumptions, which we explain in detail below. Calculations were performed in SPSS (IBM Corp. Released 2013. IBM SPSS Statistics for Windows, Version 22.0).

RG-NACT: The tps for the group of false-unfavourable and false-favourable patients were derived by using KMs and the formula $t p\left(t_{u}\right)=1-\exp \{H(t-u)-H(t)\} \quad$ [26], where $u$ is the length of the Markov cycle (1 year) and $H$ is the cumulative hazard. Data for the KM of RFS came from 25 relapsed patients from Rigter et al. [10], and that of BCSS, from literature [27]. The tps of relapse and breast cancer death for the true-favourable and trueunfavourable patients were assumed to be zero at all times, as these patients do not relapse nor die from breast cancer (see Table 2). Conventional-NACT: tps were derived from KM curves, with data from the complete dataset of Rigter et al. [10] for the RFS curve and data from literature [27] for the BCSS curve. The formula to derive tps was: $t p(t u)=1-\exp \{1 / \tau(H(t-u)-H(t))\}$ [26], where $\tau$ is the treatment effect or hazard ratio (HR) of RG-NACT vs. conventional-NACT. This formula allowed calculating the tps from a "hypothetical" control arm, which was inexistent in the Rigter et al. [10] study. The used HRs were 0.5 for the RFS curve, and 0.6 for the BCSS curve. Both HRs were derived from literature. They were set equal to the reported HR of DFS and OS in a similar population of ER-positive breast cancers where RGNACT vs. conventional-NACT was being compared [11]. As these assumptions could affect our cost-effectiveness results, we performed a one-way and two-way sensitivity analysis (SA) to the HRs (range $0.1-1.5$ ).

The tps of non-BC related deaths (i.e., transition from any state to D) were accounted for by using Dutch life tables [28]. The occurrence of vomiting, neutropenia, HFS and desquamation under $3 \times \mathrm{AC}$ and $3 \times \mathrm{DC}$, were derived from literature [24]. When a patient received both $3 \times \mathrm{AC}$ and $3 \mathrm{xDC}$ the probability of vomiting and neutropenia was represented as the combined probability of two independent events $\left(\mathrm{P}(\mathrm{A}\right.$ and $\left.\mathrm{B})=\mathrm{P}(\mathrm{A}){ }^{*} \mathrm{P}(\mathrm{B})\right)$. The probability of occurrence of $\mathrm{CHF}$ due to the administration of anthracyclines was accounted for in the 1st-year of the model and was dose-dependent: $0.2 \%$ with $3 \times \mathrm{AC}$ and $1.7 \%$ with 6xAC [23]. Also the probability of incidental findings at 
Table 2 Definitions of true-favourable, false-favourable, true-unfavourable and false-unfavourable used in our study

\begin{tabular}{ll}
\hline Group of patients & Definition \\
\hline True favourable & $\begin{array}{l}\text { Patient that is classified as favourable at monitoring } \\
\text { (criteria [7]), continues receiving NACT 1, and after } \\
5 \text { years of follow up is classified as favourable due } \\
\text { to absence of relapse event }\end{array}$ \\
False favourable & $\begin{array}{l}\text { Patient that is classified as favourable at monitoring } \\
\text { (criteria [7]), continues receiving NACT 1, and after } \\
5 \text { years of follow up is classified as unfavourable } \\
\text { due to presence of relapse event }\end{array}$ \\
True unfavourable & $\begin{array}{l}\text { Patient that is unfavourable at monitoring } \\
\text { (criteria [7]), switches to NACT 2, and after } 5 \text { years } \\
\text { of follow up is classified as favourable due to absence } \\
\text { of relapse event (the underlying assumption is that the } \\
\text { patient was not responding to NACT1 but did to NACT 2, } \\
\text { thereby demonstrating that monitoring classified the } \\
\text { patient properly) }\end{array}$ \\
& $\begin{array}{l}\text { Patient that is unfavourable at monitoring } \\
\text { (criteria [7]), switches to NACT 2, and after } 5 \text { years } \\
\text { of follow up is classified as unfavourable due to } \\
\text { presence of relapse event (the underlying } \\
\text { assumption is that the patient was responding } \\
\text { to NACT1 and did not to NACT 2, thereby } \\
\text { demonstrating that monitoring classified } \\
\text { the patient wrongly) }\end{array}$
\end{tabular}

although we are aware that in the 'False favourable' group there could be patients irresponsive to both NACT 1 and 2, as the design of the RG-NACT does not allow distinguishing them, we had to make such an assumption

MRI was accounted for in that year [29]. The frequency of MDS and AML events was based on cumulative doses of anthracycline and cyclophosphamide [25]. Patients whose NACT was interrupted to treat toxicities were still assumed to benefit from NACT and the same relapse rate was applied.

\section{Costs}

Intervention costs comprise of chemotherapy, monitoring, chemotherapy-related toxicities and costs of confirming incidental findings. To calculate drug dosages we assumed patients of $60 \mathrm{Kg}$ and body-surface area of $1.6 \mathrm{~m} 2$. Drug use was derived from study protocol, and costed by using literature [30,31] and Dutch sources on costs and prices (Dutch National Health Care Institute; Dutch Healthcare Authority; Dutch Health Care Insurance Board). Chemotherapy costs included day care and one visit to the oncologist per cycle. Costs of monitoring consisted of one MRI scan [32] and one medical visit of $1 \mathrm{~h}$ (accounting for waiting time) [31]. Costs of treating toxicities were taken from literature [33-35]. Costs of confirming incidental findings were estimated as an average of "standard diagnostic imaging" (i.e., Ultrasound, $\mathrm{x}$-Ray and bone scintigraphy) using prices from the 'The Nederlandse Zorgautoriteit' (Dutch Healthcare Authority) as a proxy [32]. Health state costs, i.e., follow up costs for the DFS health state and detection plus treatment costs for the $\mathrm{R}$ health state, were derived from literature [36]. All results were reported in 2013
Euros, using exchange currencies [37] and the consumer price index to account for inflation [38].

\section{Health-Related Quality of life}

Utilities were derived from published literature. The DFS utility was 0.78 except in the 1 st-year cycle when patients either accrued the utility of the NACT regimen without toxicities i.e., 0.62 [39], the utility of the NACT regimen with toxicities i.e., 0.62 minus the utility decrements [40-42]) or the utility of anxiety in patients were incidental findings at MRI occurred i.e., 0.68 [43]. These utilities lasted for the whole cycle. The $\mathrm{R}$ utility was calculated as an average of the utility of local and distant relapse [39]. All utility weights were obtained from sources using the EuroQoL EQ-5D questionnaires, except anxiety, which was derived from a Quality of Well-Being index [43]. There is no literature to suggest an effect of monitoring on HRQoL, thus this was assumed unaltered.

\section{Scenarios and resource modelling}

Additional parameters to simulate the scenarios and to perform the resource modelling exercise were added in the model. These include a parameter reflecting the RGNACT uptake, and parameters illustrating the proportion of i) patients with MRI contraindications (impaired renal function due to the risk of developing Nephrogenic Systemic Fibrosis (NSF) [44], presence of ferrous body parts like peacemaker (mean of values reported in [45-47], and claustrophobia [48]), ii) patients with NSF [49], iii) patients with malignant incidental findings [30] and iv) MRI technologists with acute transition symptoms (ATS) [50].

\section{Cost-effectiveness analysis}

The 5-year cumulative outcomes (health benefits and costs) were simulated for a cohort of 6306 individuals. The cost-effectiveness outcome measure was the incremental cost-effectiveness ratio (ICER), which is the difference in expected costs (per patient) divided by the difference in expected effects expressed as (quality-adjusted) life-years ((QA)LYs)) of treating one hypothetical cohort with RGNACT vs. treating an identical cohort with conventionalNACT. For the current implementation scenario, we compared the expected costs and QALYs of a cohort as treated with conventional-NACT, to the costs and QALYs of a cohort partially treated with RG-NACT, as dictated by the implementation rate and MRI contraindications. Patients where RG-NACT was not implemented or MRI was contraindicated were modelled as receivers of conventionalNACT. The full implementation scenario was modelled in the same way, except that the RG-NACT strategy was now applied to all patients in the cohort, except those with MRI contraindications receiving conventional-NACT. 
Table 3 Input model parameters

\begin{tabular}{|c|c|c|c|c|c|c|}
\hline Parameter & & mean & SE & Parameters $^{a}$ & Distribution & Source \\
\hline \multicolumn{7}{|l|}{ Clinical data } \\
\hline \multicolumn{7}{|l|}{ Monitoring performance $\mathrm{e}^{\mathrm{b}}$ (proportions) } \\
\hline True favourable & & 0,53 & 0,04 & $0,53 / 0,04$ & Dirichlet & [10] \\
\hline True unfavourable & & 0,24 & 0,05 & $0,24 / 0,05$ & Dirichlet & [10] \\
\hline False favourable & & 0,17 & 0,07 & $0,17 / 0,07$ & Dirichlet & [10] \\
\hline False unfavourable & & 0,07 & 0,09 & $0,07 / 0,09$ & Dirichlet & {$[10]$} \\
\hline \multicolumn{7}{|l|}{ Chemotherapy related toxicities } \\
\hline \multirow[t]{2}{*}{ Vomiting } & $3 \times A C$ & 0,05 & 0,02 & $5 / 98$ & beta & [24] \\
\hline & $3 \times D C$ & 0,24 & 0,04 & $24 / 77$ & beta & [24] \\
\hline HFS & $3 \times D C$ & 0,22 & 0,04 & $23 / 80$ & beta & [24] \\
\hline \multirow[t]{2}{*}{ Neutropenia } & $3 \times A C$ & 0,85 & 0,04 & $86 / 15$ & beta & [24] \\
\hline & $3 \times D C$ & 0,72 & 0,04 & $74 / 29$ & beta & [24] \\
\hline Desquamation & $3 \times D C$ & 0,05 & 0,02 & $5 / 98$ & beta & [24] \\
\hline \multirow[t]{2}{*}{$\mathrm{CHF}$} & $3 \times A C$ & 0,002 & 0,20 & $1 / 359$ & beta & {$[23]$} \\
\hline & $6 \times A C$ & 0,02 & 0,60 & $11 / 349$ & beta & [23] \\
\hline \multirow[t]{2}{*}{ AML/MDS } & $3 \times A C$ & 0,003 & 0,001 & $12 / 4471$ & beta & [25] \\
\hline & $6 \times A C$ & 0,005 & 0,001 & $12 / 2372$ & beta & {$[25]$} \\
\hline \multicolumn{7}{|l|}{ Transition probabilities } \\
\hline \multicolumn{7}{|l|}{ Relapse } \\
\hline \multirow[t]{5}{*}{ RG-NACT; False favourable/unfavourable } & Tp1 & 0,14 & 0,06 & $4 / 24$ & beta & [10] \\
\hline & Tp2 & 0,29 & 0,08 & $8 / 20$ & beta & [10] \\
\hline & Tp3 & 0,47 & 0,09 & $13 / 15$ & beta & [10] \\
\hline & Tp4 & 0,44 & 0,09 & $12 / 16$ & beta & {$[10]$} \\
\hline & Tp5 & 0,40 & 0,09 & $11 / 17$ & beta & [10] \\
\hline RG-NACT; True favourable/unfavourable & $T p 1^{2}-5$ & 0,00 & NA & - & fixed & assumption \\
\hline HR RFS (RG-NACT vs. conventional-NACT) & & 0,50 & 0,20 & $0,50 / 0,20$ & Normal truncated & assumption \\
\hline \multirow[t]{5}{*}{ Conventional-NACT } & Tp1 & 0,03 & - & - & - & {$[10]$} \\
\hline & Tp2 & 0,06 & - & - & - & [10] \\
\hline & Tp3 & 0,08 & - & - & - & {$[10]$} \\
\hline & Tp4 & 0,05 & - & - & - & {$[10]$} \\
\hline & Tp5 & 0,04 & - & - & - & [10] \\
\hline
\end{tabular}


Table 3 Input model parameters (Continued)

\begin{tabular}{|c|c|c|c|c|c|c|}
\hline \multicolumn{7}{|l|}{ Breast cancer specific death } \\
\hline \multirow[t]{5}{*}{ False favourable/unfavourable } & Tp1 & 0,00 & NA & - & fixed & assumption \\
\hline & Tp2 & 0,04 & 0,02 & $5 / 109$ & beta & {$[27]$} \\
\hline & Tp3 & 0,12 & 0,03 & $14 / 100$ & beta & {$[27]$} \\
\hline & Tp4 & 0,06 & 0,02 & $7 / 107$ & beta & {$[27]$} \\
\hline & Tp5 & 0,19 & 0,04 & $22 / 92$ & beta & {$[27]$} \\
\hline HR BCSS (RG-NACT vs. conventional-NACT) & & 0,64 & 0,13 & $0,64 / 0,13$ & normal & {$[11]$} \\
\hline \multirow[t]{5}{*}{ Conventional-NACT } & Tp1 & 0,00 & NA & - & fixed & assumption \\
\hline & Tp2 & 0,06 & - & - & - & {$[27]$} \\
\hline & Tp3 & 0,19 & - & - & - & {$[27]$} \\
\hline & Tp4 & 0,09 & - & - & - & {$[27]$} \\
\hline & Tp5 & 0,28 & - & - & - & {$[27]$} \\
\hline \multicolumn{7}{|l|}{ Utilities } \\
\hline Chemotherapy & & 0,62 & 0,04 & $94 / 58$ & beta & {$[39]$} \\
\hline Neutropenia & & 0,53 & 0,01 & $557 / 488$ & beta & {$[40]$} \\
\hline Anxiety & & 0,68 & 0,06 & $40 / 19$ & beta & {$[43]$} \\
\hline Vomiting & & 0,52 & 0,08 & $17 / 16$ & beta & [41] \\
\hline HFS & & 0,50 & 0,10 & $12 / 12$ & beta & [41] \\
\hline Desquamation & & 0,59 & 0,01 & $1041 / 721$ & beta & {$[40]$} \\
\hline CHF (average grade III/IV) & & 0,55 & - & - & beta & {$[42]$} \\
\hline CHF grade III & & 0,59 & 0,02 & $360 / 250$ & beta & {$[42]$} \\
\hline CHF grade IV & & 0,51 & 0,05 & $52 / 50$ & beta & {$[42]$} \\
\hline MDS/MLA & & 0,26 & 0,01 & $500 / 1423$ & beta & {$[55]$} \\
\hline DFS & & 0,80 & 0,03 & $196 / 49$ & beta & {$[39]$} \\
\hline $\mathrm{R}$ (average loco-regional and metastatic) & & 0,73 & - & - & beta & {$[39]$} \\
\hline Loco-regional relapse & & 0,68 & 0,03 & $226 / 104$ & beta & [39] \\
\hline Metastatic relapse & & 0,78 & 0,04 & $104 / 30$ & beta & [39] \\
\hline \multicolumn{7}{|l|}{ Scenarios and resource modelling } \\
\hline \multicolumn{7}{|l|}{ Incidental findings } \\
\hline All & & 0,18 & 0,01 & $270 / 1265$ & beta & [29] \\
\hline Malign & & 0,20 & 0,02 & $55 / 270$ & beta & {$[29]$} \\
\hline \multicolumn{7}{|l|}{ MRI contraindications } \\
\hline Impaired renal function & & 0.07 & $0.1^{c}$ & $0.45 / 5.54$ & beta & {$[49]$} \\
\hline
\end{tabular}

Utilities

Chemotherapy

scharios and resource modelling 
Table 3 Input model parameters (Continued)

\begin{tabular}{|c|c|c|c|c|c|c|c|c|}
\hline \multicolumn{2}{|c|}{ Gadolinium allergy } & & 0.0003 & $0.01^{d}$ & $0.08 / 29$ & - & & [44] \\
\hline \multicolumn{2}{|c|}{ Body ferrous parts } & & 0.58 & 0.1 & $0.26 / 4.21$ & beta & & [45] \\
\hline \multicolumn{2}{|c|}{ Claustrophobia } & & 0.02 & 0.1 & $0.02 / 0.94$ & beta & & {$[48]$} \\
\hline \multicolumn{2}{|l|}{ Uptake } & & 0.04 & & $20-100 \%$ & fixed & & assumption \\
\hline \multicolumn{2}{|c|}{ MRI technologists with ATS } & & 0.26 & & & fixed & & {$[50]$} \\
\hline \multicolumn{9}{|l|}{ Costs } \\
\hline \multicolumn{2}{|l|}{ Parameter } & Unit costs & Unit measure & Mean resource use & Mean cost & $S E^{\mathrm{e}}$ & Distribution & Source \\
\hline \multicolumn{9}{|l|}{ Chemotherapy } \\
\hline \multirow[t]{7}{*}{$6 \times A C$} & Doxorubicin & $€ 204$ & $90 \mathrm{mg}$ & 5,3 & $€ 1306$ & $€ 326$ & Gamma & [31] \\
\hline & Cyclophosphamide & $€ 45$ & $1080 \mathrm{mg}$ & 6,4 & $€ 239$ & $€ 60$ & Gamma & {$[31]$} \\
\hline & Peg-filgrastim & $€ 849$ & $1 \mathrm{mg}$ & 6 & $€ 5096$ & $€ 1274$ & Gamma & {$[56]$} \\
\hline & Pharmacy preparation & $€ 45$ & Per course & 6 & $€ 267$ & 67 & Gamma & $\mathrm{NKI}$ \\
\hline & Day care & $€ 286$ & Day & 6 & $€ 1718$ & $€ 430$ & Gamma & {$[30]$} \\
\hline & Oncologist's visit & $€ 109$ & Visit & 6 & $€ 653$ & $€ 163$ & Gamma & [31] \\
\hline & Total & & & & $€ 9279$ & & & \\
\hline \multirow[t]{9}{*}{$3 \times A C / 3 \times D C$} & Doxorubicin & $€ 204$ & $90 \mathrm{mg}$ & 3,2 & $€ 653$ & $€ 163$ & Gamma & [31] \\
\hline & Cyclophosphamide & $€ 45$ & $1080 \mathrm{mg}$ & 2,7 & $€ 120$ & $€ 30$ & Gamma & [31] \\
\hline & Peg-filgrastim & $€ 849$ & $1 \mathrm{mg}$ & 3 & $€ 2548$ & $€ 637$ & Gamma & {$[56]$} \\
\hline & Docetaxel & $€ 959$ & $108 \mathrm{mg}$ & 3,3 & $€ 3195$ & $€ 799$ & Gamma & [31] \\
\hline & Capecitabine & $€ 27$ & $4500 \mathrm{mg}$ & 29,9 & $€ 821$ & $€ 205$ & Gamma & [31] \\
\hline & Pharmacy preparation & $€ 45$ & Per course & & $€ 267$ & $€ 67$ & Gamma & NKI \\
\hline & Day care & $€ 286$ & Day & 6 & $€ 1718$ & $€ 430$ & Gamma & {$[30]$} \\
\hline & Oncologist's visit & $€ 109$ & Visit & 6 & $€ 653$ & $€ 163$ & Gamma & [31] \\
\hline & Total & & & & $€ 9974$ & & & \\
\hline \multicolumn{9}{|l|}{ Monitoring } \\
\hline \multicolumn{9}{|l|}{ MRI scan } \\
\hline \multicolumn{2}{|l|}{ Hospital costs } & $€ 163$ & Scan & 1 & $€ 163$ & $€ 41$ & Gamma & \\
\hline \multicolumn{2}{|l|}{ Specialists fees } & $€ 52$ & Scan & 1 & $€ 52$ & $€ 13$ & Gamma & \\
\hline \multicolumn{2}{|l|}{ Total } & & & & $€ 215$ & & & \\
\hline \multicolumn{2}{|c|}{ Confirm incidental findings } & $€ 149$ & Episode & 1 & $€ 149$ & $€ 37$ & Gamma & \\
\hline \multicolumn{9}{|c|}{ Chemotherapy related toxicities } \\
\hline \multicolumn{2}{|l|}{ Neutropenia } & $€ 14397$ & Episode & 1 & $€ 14397$ & $€ 425$ & Gamma & {$[35]$} \\
\hline \multicolumn{2}{|l|}{ Vomiting } & $€ 92$ & Episode & 1 & $€ 92$ & $€ 23$ & Gamma & [57] \\
\hline
\end{tabular}


Table 3 Input model parameters (Continued)

\begin{tabular}{|c|c|c|c|c|c|c|c|c|}
\hline $\mathrm{CHF}$ & & $€ 18225$ & Episode & 1 & $€ 18225$ & $€ 4556$ & Gamma & [33] \\
\hline MDS/MLA & & $€ 112946$ & Episode & 1 & $€ 112946$ & $€ 28236$ & Gamma & {$[58,59]$} \\
\hline \multicolumn{9}{|l|}{ Health states } \\
\hline \multirow[t]{3}{*}{ DFS } & In \& out -patient & $€ 2793$ & Episode & 1 & $€ 2793$ & $€ 563$ & Gamma & [36] \\
\hline & Drugs & $€ 79$ & Episode & 1 & $€ 79$ & $€ 20$ & Gamma & [36] \\
\hline & Total & & & & $€ 2872$ & & & \\
\hline \multirow[t]{7}{*}{$\mathrm{R}$} & Local relapse & & & & & & & \\
\hline & In \& out -patient & $€ 12497$ & Episode & 1 & $€ 12497$ & $€ 1692$ & Gamma & [36] \\
\hline & Drugs & $€ 2336$ & Episode & 1 & $€ 2336$ & $€ 584$ & Gamma & [36] \\
\hline & Distant metastasis & & & & & & & \\
\hline & In \& out -patient & $€ 11645$ & Episode & 1 & $€ 11645$ & $€ 1346$ & Gamma & [36] \\
\hline & Drugs & $€ 5772$ & Episode & 1 & $€ 5772$ & $€ 1443$ & Gamma & [36] \\
\hline & Total & & & & $€ 16125$ & & & \\
\hline$B C$ death & & $€ 8296$ & Episode & 1 & $€ 8296$ & $€ 2074$ & Gamma & [36] \\
\hline
\end{tabular}

Abbreviations: SE standard error, AC cyclophosphamide, doxorubicine; DC docetaxel, capecitabine; HFS hand-food-syndrome, CFH congestive heart failure, $A M L / A D M$ acute myeloid leukaemia/myelodysplastic syndrome, $M R I$ magnetic resonance imaging, tp transition probability, HR hazard ratio, RG-NACT response guided neoadjuvant chemotherapy, NACT neoadjuvant chemotherapy, DFS disease free survival, $R$ relapse, RFS relapse free survival, BCSS breast cancer specific survival, $B C$ breast cancer, ATS acute transition symptom, NKI Netherlands Cancer Institute

airichlet distribution: mean/SE, Beta distribution: $\alpha / \beta$, Normal distribution: mean/SE

'We derived these proportions with the dataset of Rigter et al., as explained in the section 'clinical input parameters' and following the definitions of 'Table 2 '

${ }^{c}$ We assumed a $S E=0.1$
${ }^{d}$ We assumed a $S E=0.01$

$\mathrm{d}$ We assumed a $\mathrm{SE}=0.01$
${ }^{e}$ We assumed $\mathrm{SE}=0.25$ when this was not available from literature 
We performed a probabilistic sensitivity analysis (PSA) after assigning a distribution to each model parameter following the recommendations by Briggs et al. [38]. A beta distribution was assigned to binomial data such as toxicities and transition probabilities, a dirichlet distribution to the proportions of true/false favourable/unfavourable patients, and a gamma distribution to utilities and costs (Table 3). The uncertainty surrounding the model results was presented as cost-effectiveness acceptability curves (CEAC), which reflect the probability of each alternative to be cost-effective across a range of threshold values for cost-effectiveness. We discounted future costs and health effects at a $4 \%$ and $1.5 \%$ yearly rate respectively, according to the Dutch guidelines on health-economics evaluations [51]. A strategy was considered cost-effective if the ICER did not exceed the willingness-to-pay threshold of $€ 20.000 / Q A L Y$.

\section{Resource modelling analysis}

We estimated the health services required and the health outcomes experienced in each strategy. Health services required included: number of 1) MRI scans performed, 2) patients scanned per MRI, 3) Full-time equivalent (FTE) MRI technologists, 4) FTE breast radiologists and 5) confirmation of incidental findings. Health outcomes included: number of 1) relapses prevented, 2) breast cancer deaths prevented, 3) excluded patients due to contraindications, 4) patients with adverse events (including NSF, CHF and AML/ADS), 5) patients with anxiety due to incidental findings, 6) patients with malignant incidental findings, and 7) fte MRI technologists with ATS. These outcomes were analysed deterministically for the current and full implementation scenarios and expressed for the 6306 ER-positive/HER2-negative breast cancer women. A detailed description of the calculations and sources for each outcome is presented in (Table 4).

Volumes of health services needed were also calculated at the hospital level, which required determining the number of hospitals expected to offer RG-NACT under each scenario. For current implementation, we assumed RGNACT to be used in the 16 hospitals of the largest Dutch hospital network currently involved in the RG-NACT trial NCT01057069 (Clinical Trials.gov). Although this trial excludes ER+ patients, we expected involved hospitals to have endorsed RG-NACT in other subtypes with single institution studies, as is the case in the NKI. For the full implementation, we considered all 113 hospitals (locations) with MRI that deliver cancer treatment (i.e., university, general and specialized hospitals), as identified from the database published by the National Public Health Atlas [52]. The presence and quantity of MRI scans per hospital was either taken from that hospital's website or based on literature [50], indicating 3 MRIs per academic hospital and 1 per general hospital.
As increasing RG-NACT uptake from 4 to $100 \%$ is not realistic in a short time-frame, we explored the resource requirements and health outcomes across a range of implementation rates via one-way SA including 20, 40, 60 and $80 \%$ uptake.

All assumptions made were confirmed by an experienced MRI technologist in a general hospital. One-way SAs on one key-assumptions was done: 'the time required by a breast radiologist for MRI scan interpretation' (range 6.8-15 $\mathrm{min}$ ).

\section{Results}

\section{Cost-effectiveness analysis}

At current implementation (4\%) RG-NACT was expected to result in 0.005 QALYs gains and savings of $€ 13$ per patient. Under full implementation, RG-NACT is expected to generate 0.12 additional QALYs and savings of $€ 328$ per patient (Table 5 ). In both scenarios, RGNACT is expected to dominate (be more effective and less costly) than conventional-NACT. The results of the PSAs show that at a willingness to pay threshold of $€ 20.000 / Q A L Y, R G-N A C T$ is expected to be the optimal strategy under the current and full implementation scenarios, with 94 and $95 \%$ certainty respectively (Fig. 2).

SAs of RFS and BCSS hazard ratios (baseline values of 0.5 and 0.64 respectively), invariably showed the RGNACT strategy to be cost-effective (Table 4). Even when LYs were slightly higher in the conventional-NACT arm (i.e., with HRs of $>1$ ), the better quality of life provided by the DC treatment of the RG-NACT strategy (lower and better tolerated adverse events) maintained the incremental QALYs for the RG-NACT strategy.

\section{Resource modelling analysis}

Under the current implementation scenario we calculated that over 5-years, the RG-NACT strategy requires 218 MRI scans to be performed in the target population of 6306 women, after 40 exclusions due to contraindications. With 31 MRI scans currently used for this purpose (estimated number of MRI scans in the multicentre NCT01057069 trial), 7 patients were scanned/MRI, requiring a total of $0.2 \mathrm{fte}$ MRI technologists and $0.02 \mathrm{fte}$ breast radiologists. At the hospital level covering a population of 6306 breast cancers, 14 MRI scans would be required for the prevalent population over a 5-year timeframe. Assuming an average capacity of 2 MRI scans/hospital (estimated weighted average of MRI scans/hospital within the multicentre NCT01057069 trial), this would translate to 7 patients scanned/MRI, demanding $0.01 \mathrm{fte}$ MRI technologists and $0.001 \mathrm{fte}$ breast radiologists per hospital. In terms of health outcomes, the current implementation scenario was expected to prevent 0.4 relapses and 6 breast cancer 
Table 4 Resource modelling outcomes, sources and calculations

\begin{tabular}{|c|c|c|c|}
\hline & $\begin{array}{l}\text { Current implementation } \\
\text { (16 hospitals, } 31 \text { MRls) }\end{array}$ & $\begin{array}{l}\text { Full implementation } \\
\text { (113 hospitals, } 148 \text { MRIs) }\end{array}$ & Source \\
\hline \multicolumn{4}{|l|}{ Health services required at the country level } \\
\hline No of MRls scans performed & Calculations in Table 2 & $\begin{array}{l}\text { No of stage II-III, ER-positive/HER2-negative } \\
\text { breast cancers in the Netherlands }\end{array}$ & See Table 2 \\
\hline No of patients scanned per MRI & 'No of MRI scans performed'/31 MRIs ${ }^{\mathrm{a}}$ & 'No of MRI scans performed'/148 MRIs ${ }^{a}$ & $\begin{array}{l}\text { See } \\
\text { footnote a }\end{array}$ \\
\hline Fte MRI technologists required & $\begin{array}{l}\text { Yearly hours required of MRI technologist to perform } \\
\text { the 'No of MRIs scans performed'/Fully workable } \\
\text { hours of an MRI technologist a year }{ }^{b}\end{array}$ & idem & $\begin{array}{l}\text { See } \\
\text { footnote b }\end{array}$ \\
\hline Fte breast radiologists required & $\begin{array}{l}\text { Yearly hours required of breast radiologist to perform } \\
\text { the 'No of MRls scans performed'/Fully workable } \\
\text { hours of a breast radiologist a yearc }\end{array}$ & idem & $\begin{array}{l}\text { See } \\
\text { footnote c }\end{array}$ \\
\hline $\begin{array}{l}\text { No of confirmations of incidental } \\
\text { findings (using standard imaging) }\end{array}$ & Derived from the Markov model & idem & - \\
\hline \multicolumn{4}{|l|}{ Health services required at the hospital level } \\
\hline $\begin{array}{l}\text { No of MRIs scans performed per } \\
\text { hospital }\end{array}$ & 'No of MRI scans performed'/16 hospitals ${ }^{d}$ & 'No of MRI scans performed'/113 hospitals & $\begin{array}{l}\text { See } \\
\text { footnote d } \\
\text { and e }\end{array}$ \\
\hline $\begin{array}{l}\text { No of patients scanned per MRI per } \\
\text { hospital }\end{array}$ & $\begin{array}{l}\text { 'No of MRI scans performed per hospital'/mean } \\
\text { MRIs per hospital| }\end{array}$ & $\begin{array}{l}\text { 'No of MRI scans performed per hospital'/ } \\
\text { mean MRIs per hospital }\end{array}$ & $\begin{array}{l}\text { See } \\
\text { footnote a }\end{array}$ \\
\hline $\begin{array}{l}\text { Fte MRI technologists required per } \\
\text { hospital }\end{array}$ & $\begin{array}{l}\text { Yearly hours required of MRI technologist to perform } \\
\text { the 'No of MRI scans performed per hospital'/Fully } \\
\text { workable hours of an MRI technologist a year }\end{array}$ & idem & $\begin{array}{l}\text { See } \\
\text { footnote b }\end{array}$ \\
\hline $\begin{array}{l}\text { Fte breast radiologists required per } \\
\text { hospital }\end{array}$ & $\begin{array}{l}\text { Yearly hours required of breast radiologist to perform } \\
\text { the 'No of MRI scans performed per hospital'/Fully } \\
\text { workable hours of a breast radiologist a yearc }\end{array}$ & idem & $\begin{array}{l}\text { See } \\
\text { footnote c }\end{array}$ \\
\hline \multicolumn{4}{|l|}{ Health outcomes gained at the country level } \\
\hline No of relapses prevented & Derived from the Markov model & idem & - \\
\hline No of breast cancer deaths prevented & Derived from the Markov model & idem & - \\
\hline \multicolumn{4}{|l|}{ Health outcomes lost at the country level } \\
\hline $\begin{array}{l}\text { No of excluded patients due to } \\
\text { contraindications }\end{array}$ & Derived from the Markov model & idem & - \\
\hline No of patients with NFS & 'No of MRI scans performed'* $p$ of NSF & idem & [48] \\
\hline Fte MRI technologists with ATS & 'Fte MRI technologists required'* $p$ of ATS & idem & [49] \\
\hline No of patients with CHF & Derived from the Markov model & idem & - \\
\hline $\begin{array}{l}\text { No of patients with long term AML/ } \\
\text { ADS }\end{array}$ & Derived from the Markov model & idem & - \\
\hline $\begin{array}{l}\text { No of patients with anxiety due to } \\
\text { incidental findings }\end{array}$ & Derived from the Markov model & idem & - \\
\hline $\begin{array}{l}\text { No of patients with malignant } \\
\text { incidental findings }\end{array}$ & $\begin{array}{l}\text { 'No of confirmations of incidental findings' } \\
{ }^{*} p \text { malignant incidental findings }{ }^{f}\end{array}$ & idem & [28] \\
\hline
\end{tabular}

Abbreviations: No number, Fte full-time equivalent, MRI magnetic resonance imaging, RG-NACT response guided neoadjuvant chemotherapy; $p$ probability, NSF nephrogenic systemic fibrosis, ATS acute transient symptom, CHF chronic heart failure, DSF disease free survival, $R$ relapse, AML/ADS myelodysplastic syndrome/ acute myeloid leukaemia

Note that when a calculation refers to another outcome of the table this is always the outcome within the same column i.e., within the same implementation rate Idem means calculated equal as the left cell, but adapted to the full implementation scenario figures

${ }^{a}$ We search for this information in each hospital website. When this information was not available or unclear, we made use of literature [49] where the most frequent quantity of MRIs per type of hospital is presented (three for academic hospitals and one for general hospitals)

${ }^{b}$ Hours required of MRI technologists for the 'No of MRIs scans performed (per hospital)' in a year are calculated by assuming that a full scanning procedure requires $1 \mathrm{~h}$ of MRI technologist. Employees were assumed to work 52 weeks/year, 5 days/week i.e., 260 days/year. Of these, 40 days would be vacation and sick days, resulting thus in 220 workable days/year. Assuming workers are employed for $8 \mathrm{~h} /$ day this results in 1760 working hours/year. Yet workers need some time off during their working days i.e., breaks, assumed to be $20 \%$. Thereby, a fully workable year is of $1408 \mathrm{~h}$

'Hours required of breast radiologist for the 'No of MRIs scans performed (per hospital)' in a year are calculated by assuming a mean of 6.8 min needed for a

breast radiologist to interpret one MRI scan [53]. The workable hours a year of a breast radiologist were calculated exactly as explained in footnote 2

${ }^{d}$ Assuming its use in the biggest Dutch hospital network involved in RG-NACT (see 'resource modelling analysis' section)

${ }^{\mathrm{e}}$ Assuming its use in all Dutch hospitals (locations) with MRI expected to deliver cancer treatment (i.e., university, general and specialized hospitals)

(see 'resource modelling analysis' section)

fAfter confirming by ultrasound 
Table 5 Resource modelling and cost-effectiveness results for the current and full implementation scenarios of response-guided NACT in the Netherlands

Cost-effectiveness analysis expressed per patient

\begin{tabular}{|c|c|c|c|c|c|c|c|c|c|c|c|c|}
\hline & \multicolumn{6}{|c|}{ Current implementation (4 \%) } & \multicolumn{6}{|c|}{ Full implementation (100 \%) } \\
\hline & Costs $(€)$ & LYS & QALYS & $\Delta$ costs $(€)$ & $\triangle$ QALYS & ICER & Costs $(€)$ & LYS & QALYS & $\Delta$ costs $(€)$ & $\triangle \mathrm{QALYS}$ & ICER \\
\hline RG-NACT disc & 28013 & 4.58 & 3.46 & -13 & 0.005 & dominant $^{a}$ & 27698 & 4.64 & 3.58 & -328 & 0.12 & $\overline{\text { dominant }}$ \\
\hline RG-NACT undisC & 30362 & 4.79 & 3.62 & -14 & 0.005 & dominant & 30021 & 4.85 & 3.74 & -355 & 0.13 & dominant \\
\hline Conventional-NACT disc & 28026 & 4.58 & 3.45 & - & - & - & 28026 & 4.58 & 3.45 & - & - & - \\
\hline Conventional-NACT undisc & 30377 & 4.76 & 3.61 & - & - & - & 30377 & 4.76 & 3.61 & - & - & - \\
\hline
\end{tabular}

\begin{tabular}{|c|c|c|c|c|c|}
\hline \multicolumn{6}{|c|}{ One-way and two-way sensitivity analysis } \\
\hline \multirow[b]{2}{*}{ HR RFS } & \multirow[t]{2}{*}{ ICER } & & \multicolumn{2}{|l|}{ ICER } & \multirow[t]{2}{*}{ ICER } \\
\hline & & HR OS & & HR RFS/BCSS & \\
\hline 0.1 & $\begin{array}{l}\text { €-12857/QALY } \\
\text { (cost-effective) }\end{array}$ & 0.1 & $\begin{array}{l}1190 / \mathrm{QALY} \\
\text { (cost-effective) }\end{array}$ & $0.1 / 0.1$ & $\begin{array}{l}\text { €-922/QALY } \\
\text { (cost-effective) }\end{array}$ \\
\hline 1 & $\begin{array}{l}€ 2398 / Q A L Y \\
\text { (cost-effective) }\end{array}$ & 1 & $\begin{array}{l}€-10692 / \mathrm{QALY} \\
\text { (cost-effective) }\end{array}$ & $1 / 1$ & $\begin{array}{l}€ 1139 / \mathrm{QALY} \\
\text { (cost-effective) }\end{array}$ \\
\hline 1.5 & $\begin{array}{l}€ 9367 / \text { QALY } \\
\text { (cost-effective) }\end{array}$ & 1.5 & $\begin{array}{l}€-15507 / Q A L Y \\
\text { (cost-effective) }\end{array}$ & $1.5 / 1.5$ & $\begin{array}{l}€ 10299 / \mathrm{Q} A \mathrm{~L} \\
\text { (cost-effective) }\end{array}$ \\
\hline
\end{tabular}

\begin{tabular}{|c|c|c|c|}
\hline \multicolumn{4}{|c|}{ Resource modelling analysis expressed in relation to the Dutch population of ER-positive/HER2-negative breast cancer women $(n=6306)^{c}$} \\
\hline & $\begin{array}{l}\text { Current implementation } \\
\text { (16 hospitals, } 31 \mathrm{MRIs})\end{array}$ & $\begin{array}{l}\text { Full implementation } \\
\text { (113 hospitals, } 148 \mathrm{MRIs} \text { ) }\end{array}$ & $\begin{array}{l}\text { Transition from current to } \\
\text { full implementation }\end{array}$ \\
\hline \multicolumn{4}{|l|}{ Health services required at the country level } \\
\hline No of MRls scans performed & 218 & 5335 & +5117 \\
\hline No of patients scanned per MRI & 7 & 36 & +29 \\
\hline Fte MRI technologists & 0.2 & 3.8 & +3.6 \\
\hline \multirow[t]{2}{*}{ Fte breast radiologists } & 0.02 & 0.4 & +0.4 \\
\hline & $0.04^{\mathrm{b}}(\uparrow 121 \%)$ & $0.95^{\mathrm{b}}(\uparrow 121 \%)$ & \\
\hline $\begin{array}{l}\text { No of confirmations of incidental findings } \\
\text { (using standard imaging) }\end{array}$ & 38 & 939 & +901 \\
\hline \multicolumn{4}{|l|}{ Health services required at the hospital level } \\
\hline No of MRIs scans performed per hospital & 14 & 47 & +33 \\
\hline No of patients scanned per MRI per hospital & 7 & 36 & +29 \\
\hline Fte MRI technologists per hospital & 0.01 & 0.03 & +0.02 \\
\hline \multirow[t]{2}{*}{ Fte breast radiologists per hospital } & 0.001 & 0.004 & +0.003 \\
\hline & $0.002^{\mathrm{b}}(\uparrow 121 \%)$ & $0.001^{b}(\uparrow 121 \%)$ & \\
\hline \multicolumn{4}{|l|}{ Health outcomes gained at the country level } \\
\hline No of relapses prevented & 0.4 & 9 & +9 \\
\hline No of breast cancer deaths prevented & 6 & 149 & +143 \\
\hline \multicolumn{4}{|l|}{ Health outcomes lost at the country level } \\
\hline No of excluded patients due to contraindications & 40 & 971 & +931 \\
\hline No of patients with NFS & 0.07 & 2 & +2 \\
\hline Fte MRI technologists with acute transient symptom & 0.04 & 0.9 & +1 \\
\hline No of patients with CHF & 106 & 83 & -23 \\
\hline No of patients with long term AML/ADS & 23 & 21 & -2 \\
\hline No of patients with anxiety due to incidental findings & 38 & 939 & +901 \\
\hline No of patients with malignant incidental findings & 8 & 192 & +184 \\
\hline
\end{tabular}

Abbreviations: Disc discounted, undisc undiscounted, No number, Fte full-time equivalent, MRI magnetic resonance imaging, NSF nephrogenic systemic fibrosis, ATS acute transient symptom, CHF chronic heart failure, AML/ADS myelodysplastic syndrome/acute myeloid leukaemia

${ }^{a}$ RG-NACT is more effective and less costly than conventional NACT

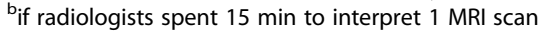

'When possible, figures were rounded to the nearest whole number 


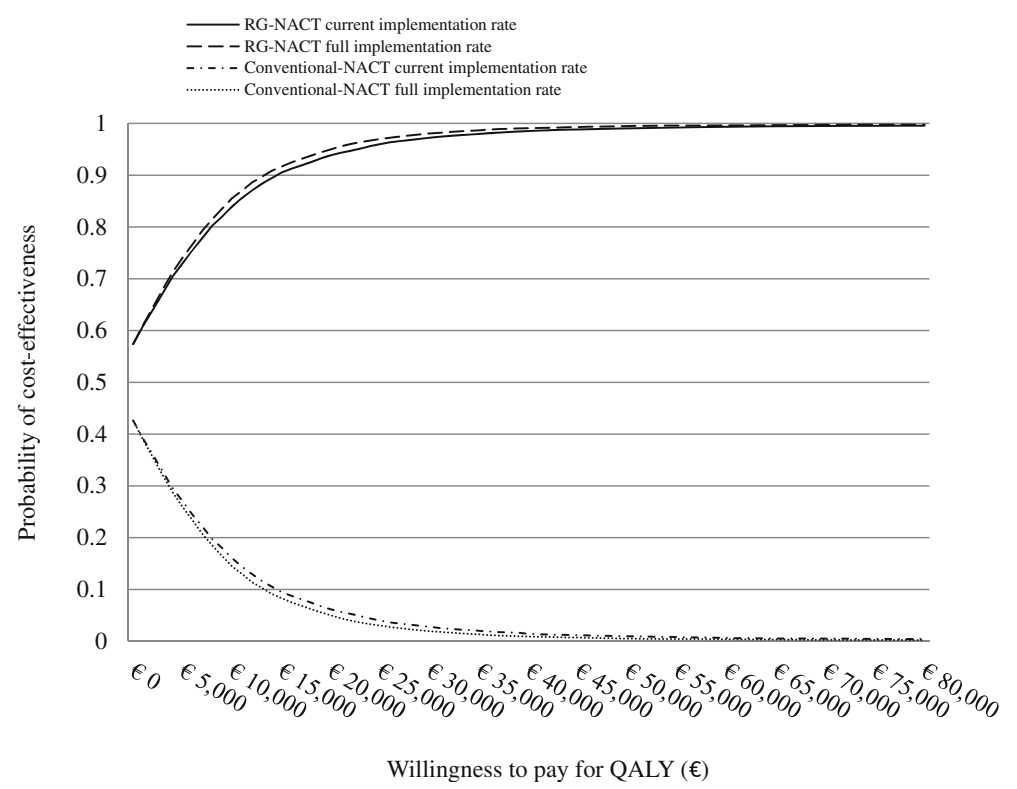

Fig. 2 Cost effectiveness acceptability curves. At a willingness to pay threshold of $€ 20.000 / Q A L Y, R G-N A C T$ is expected to be the optimal strategy with 94 and $95 \%$ certainty under the current and full implementation scenarios respectively

deaths, while yielding 0.07 patients with NSF. Besides, 106 patients would have a CHF, 23 patients would suffer from AML/ADS and 38 incidental findings were expected, of which 8 would be malignant. Of the required $0.2 \mathrm{fte}$ MRI technologists, $0.04 \mathrm{fte}$ would suffer from ATS (Table 4).

Under the full implementation scenario, we calculated that 5335 MRI scans would be needed over a 5-year period for the 6306 pertinent breast cancer population, after excluding 971 patients for contraindications. With 148 MRI scans available (estimated number of MRI scans in the estimated 113 hospitals), this would require 36 patients to be scanned/MRI for which $3.8 \mathrm{fte}$ MRI technologists and $0.4 \mathrm{fte}$ radiologists are needed. At the hospital level, 47 MRI scans are expected to be performed for the prevalent population of 6306 within 5-years. Assuming the mean MRI scans/hospital is 1.3 (estimated weighted average of MRIs/hospital within the estimated 113 hospitals), 36 patients would be scanned per MRI, requiring $0.03 \mathrm{fte}$ MRI technologists and $0.004 \mathrm{fte}$ breast radiologists per hospital. In terms of health outcomes, the full implementation scenario was expected to prevent 9 relapses and 149 breast cancer deaths, but to bring about 2 patients with NSF, 83 patients with $\mathrm{CHF}$ and 21 patients with AML/ADS. Furthermore, there are 939 incidental findings expected, of which 192 would be malignant, and $0.9 \mathrm{fte}$ MRI technologists are projected to get ATS (Table 4).

The transition from current $(4 \%)$ to full $(100 \%)$ implementation is expected to increase the number of examinations by 5117 (2347\%) countrywide or by 33
(247 \%) per hospital, consequently demanding an increase of scan utilization (for an additional 29 patients), an increase in the number MRI technologists by $3.6 \mathrm{fte}$ countrywide or by $0.02 \mathrm{fte}$ per hospital, and a marginal increase in breast radiologists by 0.4 fte countrywide or by $0.003 \mathrm{fte}$ per hospital. In terms of health outcomes, full implementation would diminish the number of breast cancer related deaths and relapses by 25 -fold (from 6 to 149) and 23-fold (from 0.4 to 9) respectively, and the number of $\mathrm{CHF}$ and AML/MDS by $\sim 0.8$-fold (from 106 to 83 ) and $\sim 0.9$ fold (from 23 to 21) respectively. However, these would come at the cost of a $\sim 25$-fold increase on health losses (additional 2 patients with NSF, 1 fte MRI technologist with ATS, 901 patients with anxiety due to presence of incidental findings, and 184 patients with confirmed malignant findings).

The one-way SA to the RG-NACT uptake rate showed that increasing rates markedly increases the number of patients with MRI contraindications, the number confirmatory scans and the number of patients with anxiety while awaiting for those (Fig. 3). Simultaneously, the number of cancer deaths, and the number of patients with CHF and AML/ADS decreased consistently (by $\sim 1.5, \sim 0.98$ and $\sim 0.95$-fold per $20 \%$ rate increase).

The results of the one-way SA on the radiologists' working pattern assumption showed that increasing the time required for MRI scan interpretation to $15 \mathrm{~min}$, increased the 'fte breast radiologists' required by $121 \%$ (Table 4). 


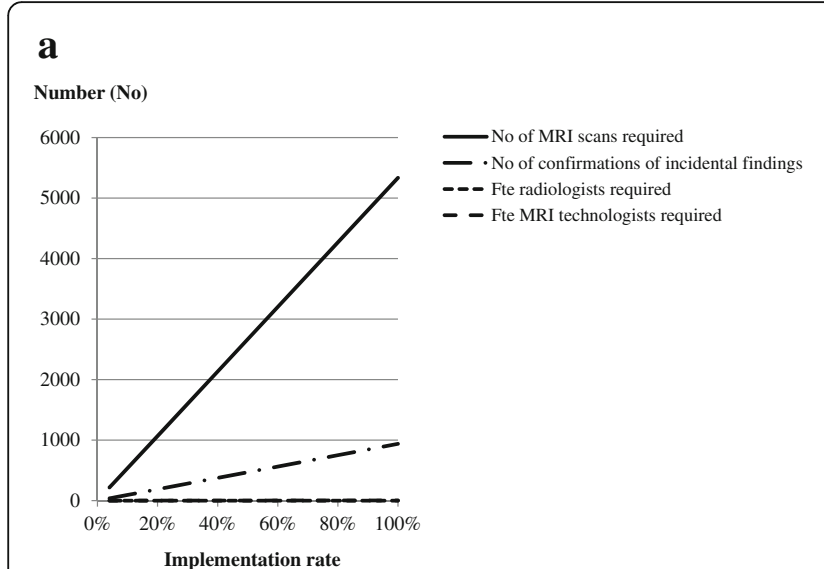

b

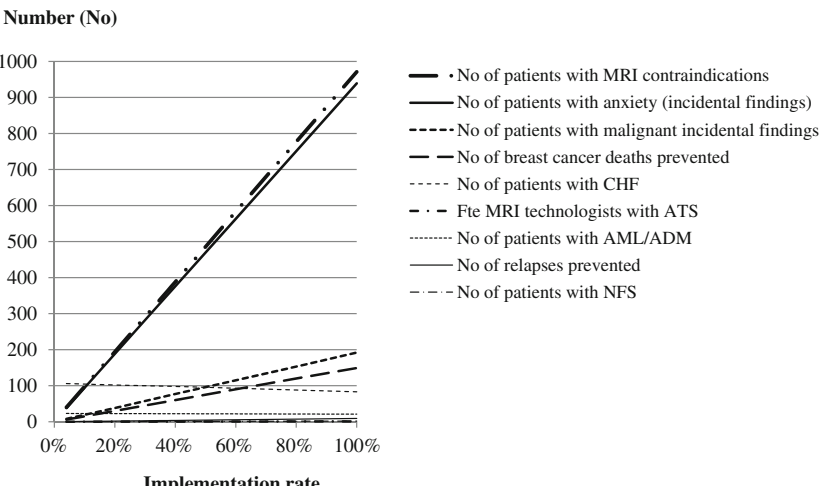

Fig. 3 Influence of implementation rates on resource modelling outcomes, (a) on health services required and (b) on health outcomes. Abbreviations: $\mathrm{No}=$ number; Fte = full-time equivalent; $\mathrm{MRI}=$ magnetic resonance imaging; $\mathrm{ATS}=$ acute transition syndrome; $\mathrm{CHF}=\mathrm{chronic}$ heart failure; $A M L / A D M=$ acute myeloid leukaemia/myelodysplastic syndrome; NFS = nephrogenic systemic fibrosis

\section{Discussion}

The aim of our study was to estimate the cost-effectiveness and resource requirements of implementing RG-NACT with MRI for ER-positive/HER2-negative breast cancer patients using The Netherlands as a case study population. As RG-NACT is an emerging treatment approach and its implementation is at its onset, we performed these analyses under a current implementation scenario of $4 \%$ uptake, and under a full implementation scenario, to anticipate the outcomes of a potential wider roll-out.

At the current $4 \%$ uptake RG-NACT is expected to be less expensive and achieve more QALYs than conventional-NACT. With higher implementation rates, more patients will be treated with this cost-saving and effective strategy, rendering RG-NACT ever more dominant. At full implementation, 0.12 additional QALYs and savings of $€ 328$ per patient are expected. This is achieved despite $15 \%$ (971 out of the 6303 patients) being treated with conventional-NACT due to MRI contraindications. In both scenarios, decision uncertainty surrounding the ICERs is low $(\sim 5 \%)$.

The main drivers of advantageous survival in the RGNACT are the HRs used to derive the hypothetical survival of the conventional-NACT strategy. Either of the HRs used (for RFS and BCSS) was below 1, thus implying less breast cancer related events in the RG-NACT strategy compared to the conventional-NACT strategy. These values were based on best available data from the GeparTrio trial [11], but this evidence is still preliminary. One- and two-way SA of these HR values demonstrated that even when survival was higher in the conventional-NACT strategy, the better quality-of-life derived from DC treatment in the RG-NACT strategy maintained the cost-effectiveness of RG-NACT.

The cost savings of RG-NACT hinge on a satisfactory diagnostic performance of MRI. Under current diagnostic performance, $79 \%$ of patients would not yield any event in the RG-NACT strategy, compared to $76 \%$ in conventional-NACT. Although the prevention of these events came at the costs of $30 \%$ of patients receiving a more expensive treatment than conventional-NACT (>€695), as treating one relapse is even more expensive (€16125), RG-NACT was still cost saving.

The resource modelling analysis showed that increasing RG-NACT uptake rates from 4 to $100 \%$ is expected to increase the number of examinations by 5117 (2347\%), consequently demanding a 5-fold increase in scans utilization, a 19-fold increase in the number MRI technologists and a 20-fold increase in the number of breast radiologists. Thereby, adapting current practice to meet these resources requires paying special attention to the availability and utilization of MRIs, as well as availability of technical personnel. For instance, fully implementing RG-NACT in the Netherlands, where 5701 MRI examinations were performed in 2013 (considering 843765 MRI examinations [15] performed in 148 MRIs), would only require 2 days of additional MRI scanning per year. However, current MRI utilization is already intense; considering 1 scan lasts $1 / 2 \mathrm{~h}$ and the scan works $8 \mathrm{~h} /$ day, 843765 MRI examinations results in 356 days of MRI scanning. As there are only 260 workable days a year, hospitals had to intensify MRI's use i.e., by adding extra evening shifts. Hence, adding 2 extra days of scanning a year would require of an even more intense MRI utilization. In terms of personnel, the number of required MRI technologists and breast radiologists are not expected to be a limiting implementation factor. While fully implementing RG-NACT would require additional $2 \mathrm{fte}$ MRI technologists and $1 \mathrm{fte}$ breast radiologists to the current $403 \mathrm{fte}$ MRI technologists and $91 \mathrm{fte}$ breast radiologists required a year, availability is estimated to be of 1700 MRI technologists countrywide [50] and 10 breast radiologists per hospital [53]. 
In terms of health outcomes gained, full implementation would diminish the number of breast cancer related deaths and relapses by 25- and 23-fold respectively, and the number of severe and costly adverse events as CHF and AML/MDS by $\sim 0.8$ - and $\sim 0.9$-fold respectively. However, these would come at the cost of a parallel $\sim 25$-fold increase in patients with NSF, MRI contraindications, MRI technologists with ATS and incidental findings causing anxiety and other diseases.

Our post-hoc analysis on resource requirements at various RG-NACT implementation rates allow identifying those that seem feasible given current resources. Considering current MRI machines and personnel capacity, RG-NACT implementation seems feasible at any rate. However, it would be interesting to further investigate whether there is sufficient capacity to handle an increase of incidental findings (requiring further diagnostic examinations), as well the costconsequences of treating those that are diagnosed as malignant.

Our study has some limitations. A limitation of the response-guided approach itself was the impossibility to distinguish in the false-unfavourable group, patients truly falsely classified at monitoring from patients irresponsive to $3 \times \mathrm{DC}$ or NACT in general. Yet, as this is inherent to guided-NACT, it was included as such in the model. Furthermore, we did not consider adjuvant treatment in our model, as the administration of this was similar between arms. Moreover, we considered AC, instead of a 3rd generation regimen containing taxanes as standard treatment because it was considered the best comparator for the used RG-NACT regimens. As costs of those are different, we performed a post-hoc one-way SA and found that RG-NACT would become more dominant due to increased cost savings. Additionally, we only accounted for direct-medical costs as other cost beyond the direct hospital-based treatment, such as productivity losses or home health care exist, are less likely to influence decision-making.

\section{Conclusion}

While the typical CEA assumes perfect implementation of the strategy under investigation, we showed the impact of implementation rates on incremental health gains and cost-savings of RG-NACT in the Dutch population of ER-positive/HER2-negative breast cancers. Furthermore, we showed that fully implementing RG-NACT generates a 24-fold increase in health benefits, but requires MRI and personnel capacity to be increased by 5 - and $\sim 20$-fold. In the Netherlands, personnel capacity is likely to be sufficient for a full implementation scenario, but MRI utilization needs to be intensified.

\section{Abbreviations}

AC, doxorubicin and cyclophosphamide; AML, acute myeloid leukaemia; ATS, acute transition symptoms; BCSS, breast cancer specific survival; CEA, cost effectiveness analysis; CEAC, cost-effectiveness acceptability curves; CHEERS, Consolidated Health Economic Evaluation Reporting Standards; CHF, congestive heart failure; D, death; DC, docetaxel and capecitabine; DFS, disease free survival; ER, oestrogen receptor; Fte, full time equivalent; HER2, human epidermal growth factor receptor-2; HFS, hand food syndrome; HR, hazard ratio; HRQoL, health related quality of life; ICER, incremental cost-effectiveness ratio; KM, Kaplan Meyer; LY, life years; MDS, myelodysplastic syndrome; MRI, magnetic resonance imaging; NACT, neoadjuvant chemotherapy; NFS, nephrogenic systemic fibrosis; NKI, Netherlands Cancer Institute; PCR, Pathologic complete response; PSA, Probabilistic sensitivity analysis; QALYS Quality-adjusted-life-years; R, Relapse; RFS, Relapse free survival; RG-NACT, Response-guided neoadjuvant chemotherapy; SA, Sensitivity analysis; Tp, Transition probabilities

\section{Acknowledgements}

The authors gratefully acknowledge Prof. dr. Sjoerd Rodenhuis for his clinical insights, and Mirjam Franken and Dr. Ruud Pijnapple for assessing the resource modelling assumptions.

\section{Funding}

This project is funded by the Center for Translational Molecular Medicine (CTMM project Breast CARE, grant no.030-104).

\section{Availability of data and materials}

All data generated or analysed during this study are included in this published article [and its supplementary information files].

\section{Authors' contributions}

AMC contributed to conception and design, data acquisition, data analysis, data interpretation and manuscript writing. LMGS contributed to conception and design, data analysis, data interpretation and manuscript writing. LSR contributed to conception and design, data acquisition and manuscript adaptations for important intellectual content. WH contributed to conception and design, data interpretation and manuscript writing. All authors have read and approve of the final version of the manuscript.

\section{Competing interests}

Lotte MG Steuten has stock ownership in Panaxea, a health economics consulting agency. Wim van Harten is a non-remunerated non-stock owner member of the supervisory board of Agendia. The authors have no other relevant affiliations or financial involvement with any organization or entity with a financial interest in or financial conflict with the subject matter or materials discussed in the manuscript apart from those disclosed.

\section{Consent for publication \\ Not applicable.}

Ethics approval and consent to participate Not applicable.

\section{Author details}

${ }^{1}$ Department of Psychosocial Research and Epidemiology, Netherlands Cancer Institute, Plesmanlaan 121, Amsterdam 1066 CX, The Netherlands. ${ }^{2}$ Hutchinson Institute for Cancer Outcomes Research, Fred Hutchinson Cancer Research Center, 1100 Fairview Ave. N., P.O. Box 19024, Seattle, USA. ${ }^{3}$ Department of Medical Oncology, The Netherlands Cancer Institute, Plesmanlaan 121, Amsterdam 1066 CX, The Netherlands. ${ }^{4}$ Department of Healthcare Technology and Services Research, University of Twente, Drienerlolaan 5, 7522 NB Enschede, The Netherlands.

Received: 14 August 2015 Accepted: 29 July 2016

Published online: 05 September 2016

\section{References}

1. Mauri D, Pavlidis N, loannidis JPA. Neoadjuvant versus adjuvant systemic treatment in breast cancer: a meta-analysis. J Natl Cancer Inst. 2005;97:188-94. 
2. Gralow JR, Zujewski JA, Winer E. Preoperative therapy in invasive breast cancer: reviewing the state of the science and exploring new research directions. J Clin Oncol. 2008;26:696-7.

3. Yeh E, Slanetz P, Kopans DB, Rafferty E, Georgian-Smith D, Moy L, et al. Prospective comparison of mammography, sonography, and MRI in patients undergoing neoadjuvant chemotherapy for palpable breast cancer. AJR Am J Roentgenol. 2005;184:868-77.

4. Shin HJ, Kim HH, Ahn JH, Kim S-B, Jung KH, Gong G, et al. Comparison of mammography, sonography, MRI and clinical examination in patients with locally advanced or inflammatory breast cancer who underwent neoadjuvant chemotherapy. Br J Radiol. 2011;84:612-20.

5. Marinovich ML, Houssami N, Macaskill P, Sardanelli F, Irwig L, Mamounas EP, et al. Meta-analysis of magnetic resonance imaging in detecting residual breast cancer after neoadjuvant therapy. J Natl Cancer Inst. 2013;105:321-33.

6. Loo CE, Teertstra HJ, Rodenhuis S, van de Vijver MJ, Hannemann J, Muller $\mathrm{SH}$, et al. Dynamic contrast-enhanced MRI for prediction of breast cancer response to neoadjuvant chemotherapy: initial results. AJR Am J Roentgenol. 2008;191:1331-8.

7. Loo CE, Straver ME, Rodenhuis S, Muller SH, Wesseling J, Vrancken Peeters $\mathrm{M}$-JTFD, et al. Magnetic resonance imaging response monitoring of breast cancer during neoadjuvant chemotherapy: relevance of breast cancer subtype. J Clin Oncol. 2011;29:660-6.

8. von Minckwitz G, Untch M, Blohmer J-U, Costa SD, Eidtmann H, Fasching PA, et al. Definition and impact of pathologic complete response on prognosis after neoadjuvant chemotherapy in various intrinsic breast cancer subtypes. J Clin Oncol. 2012;30:1796-804.

9. Untch M, Konecny GE, Paepke S, von Minckwitz G. Current and future role of neoadjuvant therapy for breast cancer. Scotl: Breast Edinb; 2014.

10. Rigter LS, Loo CE, Linn SC, Sonke GS, van Werkhoven E, Lips EH, et al. Neoadjuvant chemotherapy adaptation and serial MRI response monitoring in ER-positive HER2-negative breast cancer. Br J Cancer. 2013;109:2965-72.

11. von Minckwitz G, Blohmer JU, Costa SD, Denkert C, Eidtmann H, Eiermann W, et al. Response-guided neoadjuvant chemotherapy for breast cancer. J Clin Oncol. 2013;31:3623-30.

12. Dakin H, Devlin N, Feng Y, Rice N, O'Neill P, Parkin D. The influence of costeffectiveness and other factors on NICE decisions. Health Econ. 2014;24.

13. Thokala P, Dixon S, Jahn B. Resource modelling: The missing piece of the HTA Jigsaw? Pharmacoeconomics. 2014;33(3):193-203.

14. Husereau D, Drummond M, Petrou S, Carswell C, Moher D, Greenberg D, et al. Consolidated Health Economic Evaluation Reporting Standards (CHEERS) - explanation and elaboration: a report of the ISPOR Health Economic Evaluation Publication Guidelines Good Reporting Practices Task Force. Value Health. 2013;16:231-50.

15. OECD. Health at a Glance 2013, OECD indicators [Internet]. 2013. Available from: http://www.oecd-ilibrary.org/social-issues-migration-health/health-at-aglance-2013_health_glance-2013-en.

16. Medtronic. Pacemakers and MRI Trends [Internet]. [cited 2015 Jan 21]. Available from: http://www.medtronic.com/mrisurescan-us/mri_ pacemakers trends.html.

17. Coburn N, Przybysz R, Barbera L, Hodgson D, Sharir S, Laupacis A, et al. CT, $\mathrm{MRI}$ and ultrasound scanning rates: Evaluation of cancer diagnosis, staging and surveillance in ontario. J Surg Oncol. 2008;98:490-9.

18. Wernli KJ, DeMartini WB, Ichikawa L, Lehman CD, Onega T, Kerlikowske K, et al. Patterns of Breast Magnetic Resonance Imaging Use in Community Practice. JAMA Int Med. 2014;174:125.

19. Ries L, Eisner M, Kosary C. SEER cancer statistics review, 1973-1999. Bethesda: National Cancer Institute; 2002.

20. Parise CA, Bauer KR, Brown MM, Caggiano V. Breast cancer subtypes as defined by the estrogen receptor (ER), progesterone receptor (PR), and the human epidermal growth factor receptor 2 (HER2) among women with invasive breast cancer in California, 1999-2004. Breast J. 2009;15:593-602.

21. Early Breast Cancer Trialists' Collaborative Group. Effects of chemotherapy and hormonal therapy for early breast cancer on recurrence and 15-year survival: an overview of the randomised trials. Lancet. 2005;365:1687-717.

22. National Cancer Institute. Common Terminology Criteria for Adverse Events (CTCAE) v4.0. http://ctep.cancer.gov/protocolDevelopment/electronic_ applications/ctc.htm

23. Swain SM, Whaley FS, Ewer MS. Congestive heart failure in patients treated with doxorubicin: a retrospective analysis of three trials. Cancer. 2003;97:2869-79.

24. Lee KS, Ro J, Nam B-H, Lee ES, Kwon Y, Kwon HS, et al. A randomized phase-III trial of docetaxel/capecitabine versus doxorubicin/ cyclophosphamide as primary chemotherapy for patients with stage I//II breast cancer. Breast Cancer Res Treat. 2008;109:481-9.

25. Smith, DeCillis A, Anderson S. National Surgical Adjuvant Breast and Bowel Project Experience. Acute myeloid leukemia and myelodysplastic syndrome after doxorubicin-cyclophosphamide adjuvant therapy for operable breast cancer: the National Surgical Adjuvant Breast and Bowel Project Experience. J Clin Oncol. 2003;21:1195-204.

26. Briggs, et al. Decision modelling for Health Economic Evaluation. Oxford: Oxford University Press; 2006.

27. Tsuji W, Teramukai S, Ueno M, Toi M, Inamoto T. Prognostic factors for survival after first recurrence in breast cancer: a retrospective analysis of 252 recurrent cases at a single institution. Breast Cancer. 2014;21:86-95.

28. Dutch National Center for Health Statistics [Internet]. http://statline.cbs.nl/ Statweb/.

29. Rinaldi $P$, Costantini M, Belli $P$, Giuliani M, Bufi E, Fubelli R, et al. Extramammary findings in breast MRI. Eur Radiol. 2011;21:2268-76.

30. Retèl VP, Joore MA, Knauer M, Linn SC, Hauptmann M, van Harten WH. Cost-effectiveness of the 70-gene signature versus St. Gallen guidelines and Adjuvant Online for early breast cancer. Eur J Cancer. 2010;46:1382-91.

31. Frederix G. Disease specific methods for economic evaluations of breast cancer therapies [Internet]. University Utrecht; 2013. Available from: http:// dspace.library.uu.nl/handle/1874/276437.

32. Dutch Healthcare Authority. DBC product-finder for tariffs [Internet]. http:// dbc-zorgproducten-tarieven.nza.nl/nzaZpTarief/Welkom.aspx.

33. Wang G, Zhang Z, Ayala C, Wall HK, Fang J. Costs of heart failure-related hospitalizations in patients aged 18 to 64 years. Am J Manag Care. 2010;16: 769-76.

34. Tina Shih $Y-C, X u Y$, Elting LS. Costs of uncontrolled chemotherapy-induced nausea and vomiting among working-age cancer patients receiving highly or moderately emetogenic chemotherapy. Cancer. 2007;110:678-85.

35. Schilling MB, Parks C, Deeter RG. Costs and outcomes associated with hospitalized cancer patients with neutropenic complications: A retrospective study. Exp Ther Med. 2011;2:859-66.

36. Lidgren $M$, Wilking $N$, Jönsson B, Rehnberg C. Resource use and costs associated with different states of breast cancer. Int J Technol Assess Health Care. 2007;23:223-31.

37. XE currency Converter [Internet]. Available from: http://www.xe.com/.

38. OECD.Stat. OECD (2013) [Internet]. Available from: http://stats.oecd.org/ index.aspx?queryid=22519\#.

39. Lidgren $M$, Wilking $N$, Jönsson B, Rehnberg C. Health related quality of life in different states of breast cancer. Qual Life Res Int J Qual Life Asp Treat Care Rehab. 2007;16:1073-81.

40. Nafees B, Stafford M, Gavriel S, Bhalla S, Watkins J. Health state utilities for non small cell lung cancer. Health Qual Life Outcomes. 2008;6:84.

41. Lloyd A, Nafees B, Narewska J, Dewilde S, Watkins J. Health state utilities for metastatic breast cancer. Br J Cancer. 2006;95:683-90.

42. Ford E, Adams J, Graves N. Development of an economic model to assess the cost-effectiveness of hawthorn extract as an adjunct treatment for heart failure in Australia. BMJ Open. 2012;2(5):e001094.

43. Coco A. The Cost-Effectiveness of Expanded Testing for Primary HIV Infection. Ann Fam Med. 2005:3:391-9.

44. Wertman R, Altun E, Martin DR, Mitchell DG, Leyendecker JR, O'Malley RB, et al. Risk of nephrogenic systemic fibrosis: evaluation of gadolinium chelate contrast agents at four American universities. Radiology. 2008;248:799-806.

45. Singer OC, Sitzer M, du Mesnil de Rochemont R, Neumann-Haefelin T. Practical limitations of acute stroke MRI due to patient-related problems. Neurology. 2004;62:1848-9.

46. Hand PJ, Wardlaw JM, Rowat AM, Haisma JA, Lindley RI, Dennis MS. Magnetic resonance brain imaging in patients with acute stroke: feasibility and patient related difficulties. J Neurol Neurosurg Psychiatry. 2005;76:1525-7.

47. Sølling C, Ashkanian M, Hjort N, Gyldensted C, Andersen G, Østergaard L. Feasibility and logistics of MRI before thrombolytic treatment. Acta Neurol Scand. 2009;120:143-9.

48. Dewey M. Claustrophobia preventing MR imaging of the breast. Radiology. 2010;256:328. author reply 328-9.

49. Coresh J, Astor BC, Greene T, Eknoyan G, Levey AS. Prevalence of chronic kidney disease and decreased kidney function in the adult US population: Third National Health and Nutrition Examination Survey. Am J Kidney Dis. 2003:41:1-12.

50. Schaap K, Christopher-De Vries Y, Slottje P, Kromhout H. Inventory of MRI applications and workers exposed to MRI-related electromagnetic fields in the Netherlands. Eur J Radiol. 2013;82:2279-85. 
51. van Roijen LH, Tan SS, Brouwmans CAM. Handliding voor kosten onderzoek'. Rotterdam: College voor zorgverzekeringen; 2010. 2010 - Guide for research costs - Methods and standard cost prices for economic evaluations in healthcarelcommissioned by the Health Care Insurance Board. [Internet]. [cited 2013 Sep 3]. Available from: about:home.

52. National Public Health Atlas. National Public Health Atlas [Internet]. [cited 2015 Jan 22]. Available from: http://www.zorgatlas.nl/zorg/ziekenhuiszorg/.

53. Radiological Society of the Netherlands RS of the N. Radiological Society of the Netherlands [Internet]. [cited 2015 Feb 27]. Available from: https:/www. radiologen.nl/12/1402/kerngegevens/general-information-radiologicalsociety-of-the-netherlands.html.

54. iKNL (Integraal Kankercentrum Nederland). Nederlandse Kankerregistratie [Internet]. Available from: http://www.cijfersoverkanker.nl/over-de-registratie12.html.

55. Barr R, Furlong W, Henwood J, Feeny D, Wegener J, Walker I, et al. Economic evaluation of allogeneic bone marrow transplantation: a rudimentary model to generate estimates for the timely formulation of clinical policy. J Clin Oncol. 1996;14:1413-20.

56. Dutch National Health Care Institute. Medicijnkosten [Internet]. Available from: http://medicijnkosten.nl/.

57. Lachaine J, Yelle L, Kaizer L, Dufour A, Hopkins S, Deuson R. Chemotherapyinduced emesis: quality of life and economic impact in the context of current practice in Canada. Support Cancer Ther. 2005;2:181-7.

58. Powers A, Faria C, Broder MS, Chang E, Cherepanov D. Hematologic complications, healthcare utilization, and costs in commercially insured patients with myelodysplastic syndrome receiving supportive care. Am Health Drug Benefits. 2012;5:455-65.

59. Uyl-de Groot CA, Gelderblom-den Hartog J, Huijgens PC, Willemze R, van Ineveld BM. Costs of diagnosis, treatment, and follow up of patients with acute myeloid leukemia in the netherlands. J Hematother Stem Cell Res. 2001;10:187-92

\section{Submit your next manuscript to BioMed Central and we will help you at every step:}

- We accept pre-submission inquiries

- Our selector tool helps you to find the most relevant journal

- We provide round the clock customer support

- Convenient online submission

- Thorough peer review

- Inclusion in PubMed and all major indexing services

- Maximum visibility for your research

Submit your manuscript at www.biomedcentral.com/submit

) Biomed Central 